Louisiana State University

LSU Digital Commons

8-1-2010

\title{
Genetic evidence for high propagule pressure and long-distance dispersal in monk parakeet (Myiopsitta monachus) invasive populations
}

\author{
Anders Gonçalves Da Silva \\ University of British Columbia Okanagan \\ Jessica R. Eberhard \\ Louisiana State University \\ Timothy F. Wright \\ New Mexico State University \\ Michael L. Avery \\ USDA APHIS National Wildlife Research Center \\ Michael A. Russello \\ University of British Columbia Okanagan
}

Follow this and additional works at: https://digitalcommons.Isu.edu/biosci_pubs

\section{Recommended Citation}

Da Silva, A., Eberhard, J., Wright, T., Avery, M., \& Russello, M. (2010). Genetic evidence for high propagule pressure and long-distance dispersal in monk parakeet (Myiopsitta monachus) invasive populations. Molecular Ecology, 19 (16), 3336-3350. https://doi.org/10.1111/j.1365-294X.2010.04749.x 
University of Nebraska - Lincoln

DigitalCommons@University of Nebraska - Lincoln

USDA National Wildlife Research Center - Staff Publications
U.S. Department of Agriculture: Animal and Plant Health Inspection Service

2010

\title{
Genetic evidence for high propagule pressure and long-distance dispersal in monk parakeet (Myiopsitta monachus) invasive populations
}

\author{
Anders Goncalves da Silva \\ University of British Columbia Okanagan \\ Jessica R. Eberhard \\ Louisiana State University \\ Timothy F. Wright \\ New Mexico State University \\ Michael L. Avery \\ USDA/APHIS/WS National Wildlife Research Center, michael.I.avery@aphis.usda.gov \\ Michael A. Russello \\ University of British Columbia Okanagan
}

Follow this and additional works at: https://digitalcommons.unl.edu/icwdm_usdanwrc

Goncalves da Silva, Anders; Eberhard, Jessica R.; Wright, Timothy F.; Avery, Michael L.; and Russello, Michael A., "Genetic evidence for high propagule pressure and long-distance dispersal in monk parakeet (Myiopsitta monachus) invasive populations" (2010). USDA National Wildlife Research Center - Staff Publications. 1256.

https://digitalcommons.unl.edu/icwdm_usdanwrc/1256

This Article is brought to you for free and open access by the U.S. Department of Agriculture: Animal and Plant Health Inspection Service at DigitalCommons@University of Nebraska - Lincoln. It has been accepted for inclusion in USDA National Wildlife Research Center - Staff Publications by an authorized administrator of DigitalCommons@University of Nebraska - Lincoln. 


\title{
Genetic evidence for high propagule pressure and long-distance dispersal in monk parakeet (Myiopsitta monachus) invasive populations
}

\author{
ANDERS GONÇALVES DA SILVA, * JESSICA R. EBERHARD,† TIMOTHY F. WRIGHT, \\ MICHAEL L. AVERY§ and MICHAEL A. RUSSELLO* \\ *Department of Biology, University of British Columbia Okanagan, 3333 University Way, Kelowna, BC, Canada, +Department \\ of Biological Sciences and Museum of Natural Science, Louisiana State University, LA, USA, ‡Department of Biology, New \\ Mexico State University, NM, USA, §USDA/APHIS/WS National Wildlife Research Center, Florida Field Station, Gainesville, \\ FL, USA
}

\begin{abstract}
The monk parakeet (Myiopsitta monachus) is a successful invasive species that does not exhibit life history traits typically associated with colonizing species (e.g., high reproductive rate or long-distance dispersal capacity). To investigate this apparent paradox, we examined individual and population genetic patterns of microsatellite loci at one native and two invasive sites. More specifically, we aimed at evaluating the role of propagule pressure, sexual monogamy and long-distance dispersal in monk parakeet invasion success. Our results indicate little loss of genetic variation at invasive sites relative to the native site. We also found strong evidence for sexual monogamy from patterns of relatedness within sites, and no definite cases of extra-pair paternity in either the native site sample or the examined invasive site. Taken together, these patterns directly and indirectly suggest that high propagule pressure has contributed to monk parakeet invasion success. In addition, we found evidence for frequent long-distance dispersal at an invasive site $(\sim 100 \mathrm{~km})$ that sharply contrasted with previous estimates of smaller dispersal distance made in the native range $(\sim 2 \mathrm{~km})$, suggesting long-range dispersal also contributes to the species' spread within the United States. Overall, these results add to a growing body of literature pointing to the important role of propagule pressure in determining, and thus predicting, invasion success, especially for species whose life history traits are not typically associated with invasiveness.
\end{abstract}

Keywords: dispersal, invasion biology, monk parakeet, Myiopsitta monachus, parrots, population genetics, propagule pressure

Received 16 February 2010; revision received 27 May 2010; accepted 3 June 2010

\section{Introduction}

A central goal of invasion biology has been to identify life history traits (intrinsic factors) that could be useful in determining species that are potential invaders (Simberloff 2009). In birds, three categories of traits are recognized that affect introduction and establishment success: (i) pre-adaptive traits; (ii) traits that favour

Correspondence: Anders Gonçalves da Silva, Fax: +61 36232 5484; E-mail: anders.goncalvesdasilva@csiro.au population growth; and (iii) traits that limit establishment success (Duncan et al. 2003). Pre-adaptive traits include the ability to disperse over large distances, which is particularly useful in reaching and identifying suitable areas for colonization (Mayr 1965), behavioural flexibility, which allows for the exploration of novel resources (Duncan et al. 2003; Wright et al. in press), and having a broad niche, which is expected to increase the chances of finding suitable resources in the novel environment (Blackburn et al. 2009a; Duncan et al. 2003). Traits that favour rapid population growth, such 
as high fecundity, reduce extinction risk associated with demographic stochasticity in small, newly introduced populations (Allendorf \& Lundquist 2003; Lande 1988; Sakai et al. 2001). Finally, a number of traits may limit establishment success; the two most commonly observed among flying birds are migratory behaviour and sexual dichromatism (Blackburn et al. 2009a,b; Duncan et al. 2003). This limitation is thought to arise from the highly specific habitat and physiological needs of migratory species, and the energy costs associated with sexual selection (Blackburn et al. 2009a,b; Cassey 2002; Duncan et al. 2003).

The monk parakeet (Myiopsitta monachus) is a successful invasive species with a native distribution restricted to southern South America and established invasive populations occurring in the United States, Europe, the Caribbean and Japan (BirdLife International 2009; Carrete \& Tella 2008). It was first introduced to the United States in the 1960s by the international pet trade and has since become established and exhibited exponential growth in a number of sites, with populations reported along the Atlantic coast from Florida to Connecticut, along the Gulf coast in Louisiana and Texas, and in Colorado, Illinois, and Oregon (Pruett-Jones et al. 2005; Van Bael \& Pruett-Jones 1996). A similar pattern is observed in Europe, where the species has a broad but patchy distribution (Strubbe \& Matthysen 2009). The success in the invasive range is mirrored in the native distribution, where the species has recently colonized new areas made available through the introduction of Eucalyptus trees (Forshaw \& Cooper 1989). Understanding the factors that have facilitated these introductions and population expansions will greatly improve our knowledge of the determinants of species invasion success.

The monk parakeet is neither migratory nor sexually dichromatic, thus it does not exhibit either of the traits commonly thought to limit establishment success in flying birds (Duncan et al. 2003). However, based on studies in the native range, the monk parakeet is considered a monogamous species that exhibits some cooperative breeding characteristics (e.g., incidental helping behaviour and colonial nesting), has one breeding season per year (often only one clutch), relatively large clutches (56 eggs) but low fledging rates (1-2 per nest), high variance in reproductive success across individuals, and delayed first reproduction (Eberhard 1998; Emlen 1990; Navarro \& Bucher 1990, 1992; Navarro et al. 1992, 1995). Observational studies in the native range have also reported that dispersal is restricted to relatively short distances of $2 \mathrm{~km}$ or less (Martín \& Bucher 1993). These traits suggest slow population growth and reduced ability to search for suitable habitat, both of which are inconsistent with the reproductive and dis- persal capacities considered essential for successful invasion in birds (Blackburn et al. 2009b; Mayr 1965). These contrasting traits represent an apparent paradox when considering the broad success of the monk parakeet in invading areas outside of their native range.

A number of hypotheses may explain the monk parakeet's invasion success in spite of possessing traits thought to limit invasiveness. First, it has become increasingly apparent that, independent of life history traits, invasion success is strongly influenced by the number of individuals introduced and the number of independent introductions, an extrinsic factor termed propagule pressure (Cassey et al. 2004; Duncan 1997; Green 1997; Hayes \& Barry 2008; Lockwood et al. 2005; Marchetti et al. 2004; Simberloff 2009; Veltman et al. 1996; Von Holle \& Simberloff 2005). As a general rule, the higher the propagule pressure, the greater the likelihood that a species will become a successful invader (Duncan 1997; Green 1997; Hayes \& Barry 2008; Von Holle \& Simberloff 2005). Introduction of large numbers of individuals has been shown to buffer against genetic bottlenecks (Simberloff 2009), with some introduced populations having similar or higher levels of genetic variation than native populations (Kolbe et al. 2004). As a result, propagule pressure may help buffer the effects of demographic stochasticity (Lockwood et al. 2005). In the case of monk parakeets in the United States, such a hypothesis is plausible given the international pet trade of wild-caught individuals, estimated to have brought thousands of monk parakeets into the country in the mid- to late-20th century alone (Lever \& Gillmor 1987; Spreyer \& Bucher 1998). The international pet trade, in general, has contributed positively to an increase in the number of successful invasive bird species (Carrete \& Tella 2008); genetic evidence in concordance with trapping records also implicates its role in facilitating monk parakeet invasions (Russello et al. 2008; Van Bael \& Pruett-Jones 1996). If propagule pressure has been high, then levels of genetic variation as measured by expected heterozygosity and allelic richness are expected to be comparable between native and invasive populations (Dlugosch \& Parker 2008; Suarez et al. 2008; Wares et al. 2005).

Second, intraspecific reproductive strategies in birds can vary in response to environmental change or population density (Rossmanith et al. 2006). Monk parakeets are described as socially monogamous; however, it has not been established whether the species is also sexually monogamous, as is expected for most socially monogamous parrots (e.g., Masello et al. 2002; Spoon 2006), or whether it displays some level of extra-pair paternity (EPP) or intra-specific brood parasitism (IBP) as in many other bird species (Arnold \& Owens 2002; Griffith et al. 2002; Petrie \& Kempenaers 1998). 
Variation across populations in levels of EPP can be associated with differences in population density, availability of food and nesting sites and genetic variation, while lack of EPP can be a strong indication that male parental care is crucial for successful reproduction (Griffith et al. 2002). Behavioural observations of monk parakeets in the native range show significant male involvement in rearing young, with males foraging for both incubating and brooding females, and for nestlings (Eberhard 1998). This level of involvement suggests that monk parakeets are probably sexually monogamous and should display minimal levels of EPP (Griffith et al. 2002). If monk parakeets are indeed sexually monogamous, such a trait is expected to increase extinction risk in small populations because of reduced mating opportunities and a consequent increase in demographic stochasticity (Bessa-Gomes et al. 2003; Legendre et al. 1999), thus reducing establishment success rate. In a scenario of high propagule pressure, however, monogamy would not present a challenge to establishment, lending support to the hypothesis that the release of a large number of individuals is one of the principal drivers of monk parakeet establishment success. Alternatively, differences in the level of EPP between native and invasive ranges could lead to the identification of novel factors not previously considered for this species (e.g., mating system flexibility contributing to reduced extinction risk in small populations, Rossmanith et al. 2006).

Finally, a meta-analysis assessing the effects of species-level traits on the establishment success of exotic birds indicates that the breadth of habitats used by a species has a particularly strong positive effect, presumably because habitat generalists are better able to cope with novel environments (Blackburn et al. 2009a). This finding is likely to be relevant to the establishment success of introduced monk parakeets. In their native range, monk parakeets inhabit a range of lowland habitats, including open forest, savannah woodland and agricultural areas, often near or within urban areas (Forshaw \& Cooper 1989). Furthermore, their native distribution encompasses both tropical and subtropical climatic zones, so they regularly encounter hot summers as well as winters with subfreezing temperatures.

Addressing the above-mentioned hypotheses may help clarify why monk parakeets have become successfully established, but they do not explain how the species has expanded across the United States. Understanding spread is just as important as understanding establishment in combating invasive species (Sakai et al. 2001). The short dispersal distances observed in the native range and the number of individuals transported during the pet trade suggests that monk parakeets mainly spread through human assis- tance, much like the brown anole (Anolis sangrei, Campbell 1996). However, an examination of Christmas bird counts (CBC) suggests that geographical expansion may be a result of population growth and dispersal rather than additional releases (Van Bael \& Pruett-Jones 1996). Two hypotheses can explain this inconsistency, either (i) Van Bael \& Pruett-Jones (1996) assessment about the drivers of monk parakeet population growth is wrong and, in fact, human-mediated spread through continuous releases has enabled colonization of new localities, or (ii) the species' dispersal capacity is larger than what has previously been reported. The current estimate of monk parakeet maximum dispersal capacity $(\sim 2 \mathrm{~km})$ is based on observations over a relatively small spatial scale (12 000 m, Martín \& Bucher 1993) when compared to observed maximal dispersal distances in birds of similar size to monk parakeets $(\sim 350 \mathrm{~km}$, Paradis et al. 1998). Thus, current estimates of dispersal capacity in monk parakeets may be significantly underestimated, with potentially important implications for their ability to spread in the invasive range.

In this study, we compared genetic variation at species-specific microsatellite loci in parakeets from a native site in Argentina and two invasive sites in the United States (Florida and Connecticut) to explore the factors contributing to monk parakeet invasion success. In particular, we addressed the following questions: (i) Is there evidence for high propagule pressure based on comparisons of patterns of genetic variation within and between native and invasive sites? (ii) Is there evidence for sexual monogamy in both native and invasive sites? and (iii) Is there genetic evidence for dispersal over larger scales in an invasive site than previously reported in the native range?

\section{Materials and methods}

\section{Sampling sites}

Samples were collected at three sites, one in the species' native range and two in the invasive range within the United States (Fig. 1). The native range site is located in the Entre Ríos province, Argentina (AR), a region identified as being a likely source for individuals for the United States pet trade (Russello et al. 2008). Samples in the invasive range were collected from the greater Miami metropolitan area in Florida (FL) and in southern Connecticut (CT) (Fig. 1).

\section{Data}

Monk parakeets often breed in multi-chambered nests that may contain more than one breeding pair, with each pair and its offspring occupying a separate 
(a)

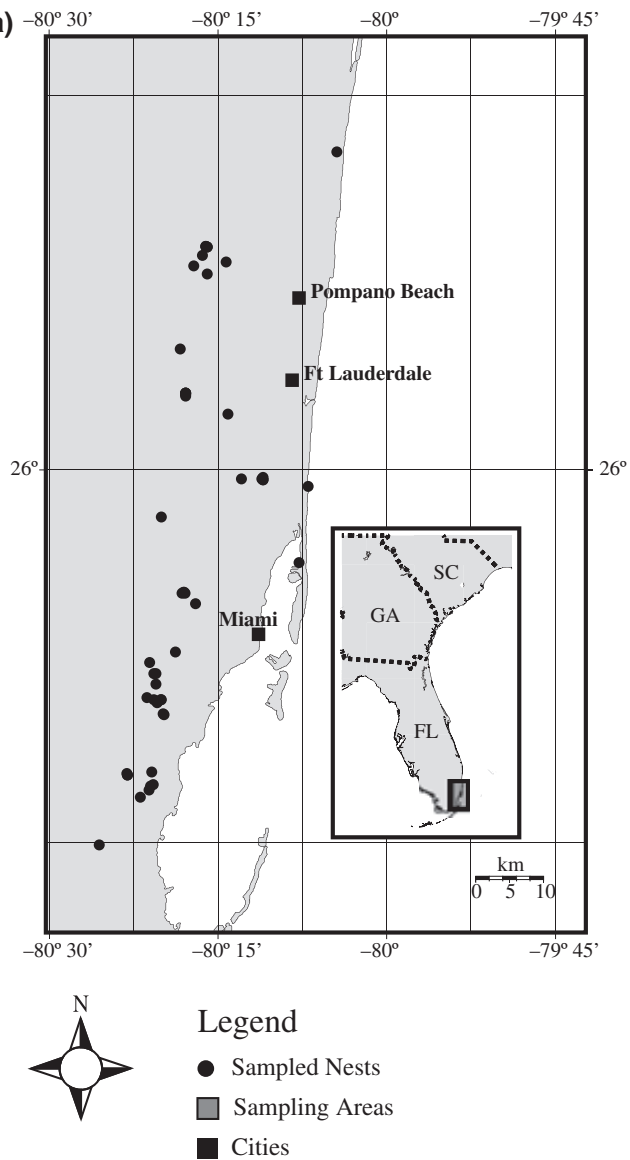

(b)
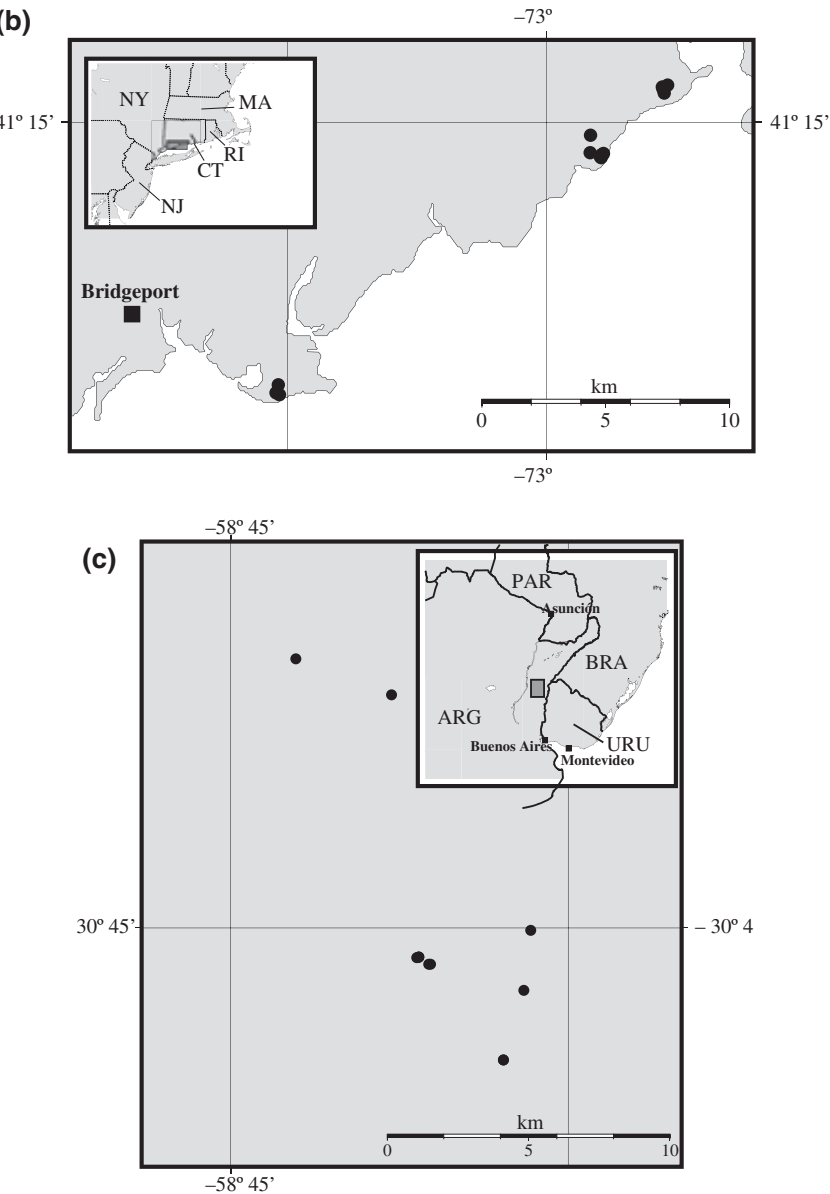

Fig. 1 Sampled monk parakeets (Myiopsitta monachus) nests across three sites. (a) In Florida, 149 individuals were sampled from 52 nests in the greater Miami metropolitan area. (b) In southern Connecticut, 46 individuals were sampled from 14 nests. (c) In Argentina, 60 individuals were sampled from 12 nests in Entre Ríos province, considered to be one of the main sources of individuals for the United States pet trade (Russello et al. 2008).

chamber (Eberhard 1998). In addition to being used for breeding, nests are used year-round by the parakeets for roosting (Forshaw \& Cooper 1989). In AR and FL, sampling occurred during the breeding season, and our sampling unit consisted of a breeding pair and juvenile offspring; three of the AR nests included a third adult who assisted the breeding pair (Eberhard 1998). In CT, sampling occurred late in the breeding season, and while samples were grouped according to chambers, it was not possible to determine whether the grouping consisted of a breeding pair and juvenile offspring. Hence forward, we refer to nests as a single chamber within a compound nest.

In AR, blood samples $\left(N_{\text {ind }}=60, N_{\text {nests }}=12\right)$ from wild individuals were collected and preserved as described by Eberhard (1998). In FL ( $N_{\text {ind }}=149$, $\left.N_{\text {nests }}=52\right)$ and CT $\left(N_{\text {ind }}=46, N_{\text {nests }}=14\right)$, tissue samples were collected by local electric utility companies and preserved at $-20{ }^{\circ} \mathrm{C}$ until processed in the laboratory. Geographical coordinates were registered for each sampling unit with a GPS unit in FL and CT. In AR, geographical coordinates were recovered from aerial photographs superimposed on geo-referenced satellite images (Fig. 1).

Genomic DNA was isolated using the QIAGEN DNeasy tissue kit following the manufacturer's protocol (Qiagen, Inc.). Individuals were typed at 10 species-specific microsatellite loci using PCR conditions described by Russello et al. (2007), Table 1. Automated fluorescent genotyping was conducted on an ABI 3730xl DNA Analyzer (Applied Biosystems, Inc.), and chromatograms were scored using GENEMAPPER ${ }^{\circledR}$ Software v4.0 (Applied Biosystems, Inc.).

All individuals were sexed using the P2/P8 primer system (Griffiths et al. 1998) following the parrot-optimized protocol described by Russello \& Amato (2001). For the AR and FL sites, we classified individuals into two age classes (adult and juveniles) either by direct observation of banded individuals at nests (AR) or by plumage (FL). In CT, unambiguous age classification 
was not possible because sampling was carried out late in the season after juveniles had moulted. Putative adults were identified because either it was the only individual sampled in a nest $\left(N_{\text {ind }}=3\right)$ or because they were the male-female pair with the smallest Queller \& Goodnight (1989) index among the individuals in the nest (i.e., the putative breeding pair; $N_{\text {ind }}=16$, $N_{\text {nests }}=8$ ). Finally, in two nests only two individuals were sampled, with pairwise relatedness indices of 0.51 and 0.20 , which we considered to be related enough to skew estimates of allele frequency distribution, and thus classified as juveniles. Therefore, we considered 19 of the 46 individuals sampled to be adults for the purpose of estimating basic genetic diversity parameters, and the remaining 27 to be juveniles. Nevertheless, because of the uncertainty surrounding the classification of adults within CT, we did not use this site to address questions related to mating or dispersal behaviour.

\section{Analysis}

Population data sets were screened for null alleles using Micro-Checker (Van Oosterhout et al. 2004). Calculations of observed and expected heterozygosity, number of alleles per locus, and tests for Hardy-Weinberg Equilibrium (HWE) and linkage disequilibrium (LD) were carried out in ArLequin v.3.11 (Excoffier et al. 2005) using default settings, adult individuals and loci with no signatures of null alleles.

Propagule pressure was inferred by comparing genetic variation between native and invasive sites, examining the partitioning of genetic variation among sites, and by testing for bottleneck signatures. First, we counted the number of alleles present at each site. To remove the effect of differing sample sizes among sites, we bootstrapped individuals within each sampling site to the smaller sample size of each comparison and recalculated the number of alleles in each site. For example, in the AR/FL comparison for example, we re-sampled 26 individuals with replacement from each site $\left(N_{\text {adults }}=26\right.$ in $\mathrm{AR}$ and $N_{\text {adults }}=91$ in FL $)$. For each comparison between source and invasive site, we generated 1000 subsamples. Second, we screened for the presence of private alleles and rare alleles across sites (alleles with inferred population allele frequency $<0.05$ ), which permits a rough indication of genetic differentiation between source and invasive sites. Third, we calculated the proportional loss of expected and observed heterozygosity, and allelic richness in invasive sites relative to the native site (Dlugosch \& Parker 2008; Suarez et al. 2008; Wares et al. 2005). To test the significance of the observed losses, we generated expected distributions of the loss of genetic diversity for each pairwise comparison by permuting individuals 1000 times and re-calculating the loss of genetic diversity. Significance was assessed at $\alpha=0.05$ and was calculated as the proportions of simulated values that were equal to or larger than the observed value. We also partitioned the genetic variation among and within native and invasive sites, and inferred fixation indices using an analysis of molecular variance (AMOVA, Excoffier et al. 1992) as implemented in ARLEQUIN 3.11. To test whether inferred fixation indices were significantly different from zero, individuals and loci were permuted as appropriate for the hierarchical level under consideration (Excoffier et al. 2005). Finally, genetic signatures of population bottlenecks were assessed for all three sites using the heterozygote excess and mode-shift tests, both implemented in the software package BotTLENECK 1.2.02 (Piry et al. 1999).

Sexual monogamy was inferred from patterns of relatedness and allele sharing among individuals, and from tests for EPP and IBP. Sexual monogamy predicts that adult-juvenile pairs within nests should have a relatedness value of 0.5 and adult-offspring pairs among nests should have a relatedness value of 0.0 (Blouin et al. 1996). In AR and FL, we calculated mean relatedness between individuals within and among nests. We also calculated mean relatedness between male/female adults and juveniles both within and among nests. Tests of significance were performed by comparing 95\% confidence intervals (95\% CI) around the mean. Because the species is generally considered to be socially monogamous with high parental investment from both females and males (Eberhard 1998; Martín \& Bucher 1993), we expected to find significantly higher relatedness within nests than among nests. Queller \& Goodnight's (1989) relatedness index was calculated for all possible pairwise combinations of individuals within each population using iREL (Gonçalves da Silva \& Russello 2010). Population allele frequencies for the calculation of relatedness values were estimated from individuals classified as adults.

Parentage assignment programs such as CERVus (Field Genetics Ltd.) (Marshall et al. 1998) require extensive demographic and observational data, in particular, estimates of number of putative parents per offspring as well as the proportion of putative parents sampled (Kalinowski et al. 2007). As these were unavailable in the present study, particularly in Florida, we investigated the possibility of EPP and IBP (Arnold \& Owens 2002; Griffith et al. 2002; Petrie \& Kempenaers 1998) using a multi-step approach. First, we identified all adult-juvenile pairs that shared at least one allele at every locus. Because there is a larger than zero probability that any two individuals will share at least one allele at every locus by chance, we implemented a Bayesian method developed by Christie (2010) to calculate the 
probability that an adult-juvenile pair that shares at least one allele at every locus is not a true parentoffspring pair given the observed allele frequency $(P(\Phi \mid \lambda))$. This measure is a function of the probability of not being a parent-offspring pair $(P(\Phi))$, and the probability of sharing at least one allele at every locus given that the pair is not a parent-offspring $(P(\lambda \mid \Phi))$. Thus, to obtain a high degree of certainty that identified pairs are true parent-offspring in any particular sample, $P(\Phi)$ or $P(\lambda \mid \Phi)$, or both, need to be low (Fig. 3 in Christie 2010). Factors that influence these parameters include the number of loci and alleles in the data set, as well as the genotyping error rate (Christie 2010). Therefore, to further decrease the chance of falsely identifying an adult-juvenile pair as a true parent-offspring pair, we used five criteria: (i) individuals with incomplete genotypes were not included in the analysis; (ii) putative pairs have a $P(\Phi \mid \lambda) \leq 0.15$, which strikes a good balance between minimizing both $P(\Phi)$ and $P(\lambda \mid \Phi)$ as inferred from Fig. 3 of Christie (2010); (iii) putative pairs have a Queller \& Goodnight (1989) relatedness index equal to or larger than the empirical cut-off value for first-order relationships described later for measuring dispersal distances; (iv) putative parents could not be at distances larger than $100 \mathrm{~m}$ from the nest of the putative offspring, the maximum observed distance between nests considered to be of the same colony in the native habitat (Eberhard 1998); and (v) inferred extra-pair parents could not have a relatedness value equal to or larger than the empirically determined cut-off value for firstorder relationship to any of the adults in the nest of the putative offspring. This latter criterion minimizes the possibility that high allele sharing is caused by firstorder adult relationship between nests. To ascertain that there was no redundancy in the second and third criteria, we regressed $P(\Phi \mid \lambda)$ onto the relatedness index. A nonsignificant relationship implies that these two criteria are complementary and useful for identifying true parent-offspring pairs.

We inferred dispersal distances in AR and FL by examining the distance between nests of first-order adult relatives. First, we simulated and calculated the relatedness index of 1000 pairs at each of four relatedness categories (unrelated, half-sibs, full-sibs and parent-offspring) following the procedure described by Russello \& Amato (2004) and implemented in iREL (Gonçalves da Silva \& Russello 2010). The distribution of relatedness values in each category was used to empirically determine cut-off values that would minimize the chance of incorrectly assigning a first-order relationship to a dyad (Russello \& Amato 2004). Previous studies have set the cut-off as the mid-point between the means of relatedness values from simulated half-sib and full-sib dyads $(\sim 0.375$, Blouin et al.
1996; Van de Casteele et al. 2001). However, this cut-off can result in false positives at levels that we deemed too high for the purposes of this study. Consequently, we set the cut-off value so that there would be $<1 \%$ chance of an unrelated pair, and less than $10 \%$ chance a half-sib pair being falsely identified as a first-order pair. We then plotted the distribution of distances between all adult pairs classified as having a first-order relationship. This strategy has been recommended for the detection of long-distance dispersal (Koenig et al. 1996), and because we focused on first-order relatives, it allows us to directly measure how far genes can travel within one generation.

\section{Results}

\section{Comparative genetic variation}

Ten loci were genotyped for 255 individuals across the three sampling sites (Fig. 1). Specifically, we sampled 12 nests in AR, with 26 adults (mean/nest $=2.16 \pm 0.57$ ) and 34 juveniles (mean $/$ nest $=2.72 \pm 2.21$ ) for a total of 60 individuals; 52 nests in FL, with 91 adults (mean/nest $=1.75 \pm 0.83$ ) and 58 juveniles (mean $/$ nest $=1.11 \pm$ 1.67) for a total of 149 individuals; and 14 nests in CT, with 19 putative adults (mean/nest $=1.36 \pm 0.84$ ) and 27 putative juveniles $($ mean $/$ nest $=1.93 \pm 2.13)$ for a total of 46 individuals. Tests for homozygote excess in Micro-Checker (Van Oosterhout et al. 2004) detected signatures for null alleles at one locus in AR (Mm054) and at two loci in FL (Mm054 and Mm098). These loci were removed from subsequent analyses. Tests for HWE and LD at individual loci within each site found no significant deviation from HWE in AR and FL, and no significant LD in AR. Significant LD was detected for loci Mm012 and Mm057 in CT, and Mm012 and Mm090 in FL. Mean expected heterozygosity was relatively high in both native and invasive sites (AR: 0.70; FL: 0.64; CT: 0.60; Table 1), as was mean observed heterozygosity (AR: 0.67, FL: 0.62, CT: 0.65; Table 1). The mean number of alleles across all loci was highest in AR and FL, while CT has considerably fewer alleles (AR: 6.50; FL: 6.00; CT: 4.00; Table 1).

To explore the role of propagule pressure, we examined patterns of genetic diversity between native and invasive sites. Among the adult individuals, we found a total of 52, 48 and 32 alleles in AR, FL and CT, respectively. Sample size-corrected comparisons of the extent of variation within sites revealed a mean number of alleles of 47.78 (95\% CI 44-51) and 40.16 (95\% CI 3644) in AR and FL, respectively; while for the AR/CT pair, we observed a mean number of alleles of 45.38 (95\% CI 41-49) and 29.65 (95\% CI 27-32), respectively. The overlap in the $95 \% \mathrm{CI}$ in the $\mathrm{AR} / \mathrm{FL}$ comparison 


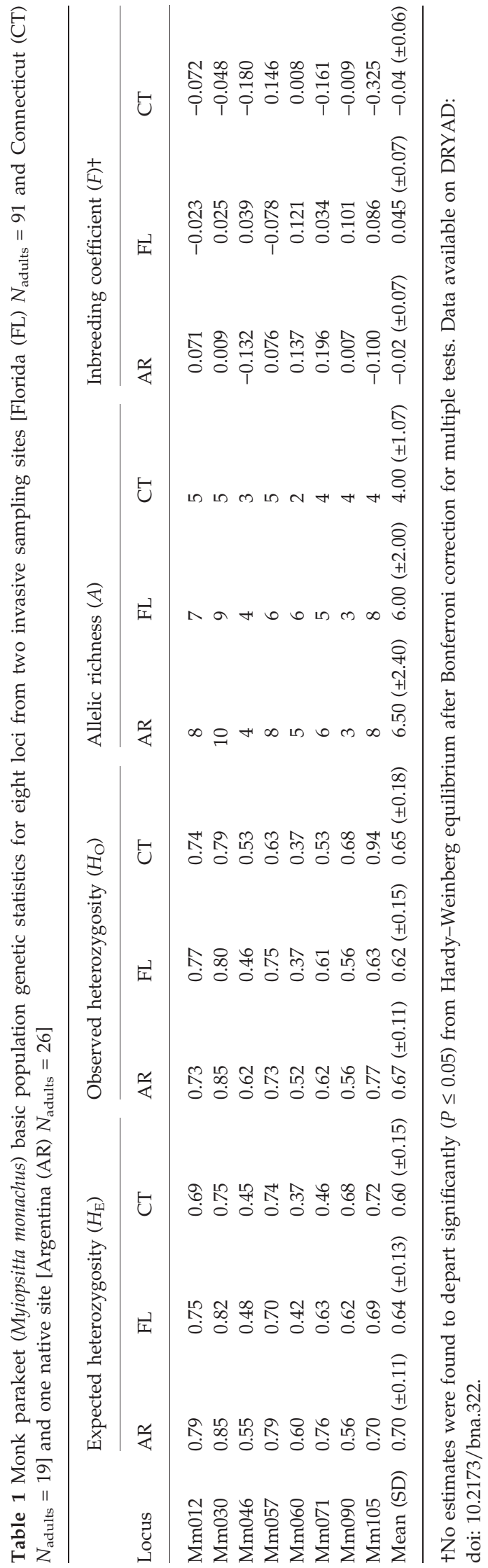

suggests a similar number of alleles between these two sites, while in the AR/CT comparison, CT has significantly fewer alleles.

Among the observed alleles, only a handful of private alleles were identified in the invasive sites. In total, 26 of the 32 alleles observed in CT were present in AR, and 38 of the 48 alleles observed in FL were present in AR. When taking into account sample size as described earlier, we found a mean of 7.36 (95\% CI 6-10) private alleles in CT and 8.96 (95\% CI 7-12) private alleles in FL, when compared to AR. Comparison of allele frequencies across sites revealed high congruence between native and invasive sites. Of the 22 rare alleles found in $\mathrm{AR}, 14$ and 15 of them were also rare in FL and CT, respectively. However, two and one of the rare alleles in AR occurred at relative frequencies higher than 0.5 in FL and CT, respectively (Data S1, Supporting information).

In terms of allelic richness and expected heterozygosity, we observed little loss of genetic diversity in FL relative to AR, while CT displayed larger losses (Table 1). For the AR/FL pair, we observed a mean loss of 5.5\% in allelic richness $(P \leq 0.144)$, a mean loss of $8.9 \%$ in expected heterozygosity $(P \leq 0.34)$ and a mean loss of $9.0 \%$ in observed heterozygosity $(P<0.05)$. For the AR/CT pair, we observed a mean loss of $32.5 \%$ in allelic richness $(P<0.05)$, a mean loss of $13.0 \%$ in expected heterozygosity $(P<0.05)$ and mean loss of $3.9 \%$ in observed heterozygosity $(P \leq 0.21)$.

The AMOVA indicated that most of the genetic variation occurred within individuals $(\sim 82 \%)$; however, a statistically significant portion was explained by the difference between the native (AR) and invasive (FL + CT) sites $(\sim 13 \%)$ and among sites within ranges $(\sim 3 \%$; Table 2). Pairwise comparisons suggest that these differences were mostly because of differentiation between $\mathrm{AR}$ and the invasive sites (FL and CT), rather than between the two invasive sites (Table 2). Finally, heterozygote excess and mode-shift tests failed to detect signatures of a genetic bottleneck in all of the three sites. However, the smaller proportional loss of heterozygosity $(13 \%)$ relative to allelic richness $(32.5 \%)$ in CT when compared to AR suggests that CT might have undergone a bottleneck event (Wares et al. 2005).

\section{Population distribution of relatedness values and tests for EPP and IBP}

$\mathrm{AR}$ and FL sites showed similar distributions of relatedness values within (mean relatedness: AR: 0.39; FL: 0.40 ) and among nests (mean relatedness: AR: -0.04 ; FL: -0.01; Table 3). The same pattern was observed when comparing adult females or males to juveniles within and among nests (Table 3). In both sites, there 
Table 2 Summary results for native and invasive range population structure analysis. (a) AMOVA table; (b) estimate of fixation indices based on AMOVA results - values significantly different from zero are in bold; and (c) pairwise genetic differentiation - above diagonal: $\Phi_{\mathrm{ST}}$; below diagonal: $P$-values

(a)

\begin{tabular}{lclc}
\hline Source & $\begin{array}{c}\text { Sum of } \\
\text { squares }\end{array}$ & $\begin{array}{l}\text { Variance } \\
\text { components }\end{array}$ & $\begin{array}{l}\text { Percentage } \\
\text { variation }\end{array}$ \\
\hline $\begin{array}{c}\text { Between native and } \\
\text { invasive ranges }\end{array}$ & 44.264 & 0.425 & 13.712 \\
$\begin{array}{l}\text { Among sites within } \\
\text { ranges }\end{array}$ & 8.299 & 0.091 & 2.944 \\
$\begin{array}{l}\text { Among individuals } \\
\text { within sites }\end{array}$ & 343.868 & 0.050 & 1.614 \\
$\begin{array}{l}\text { Within individuals } \\
\text { Total }\end{array}$ & 338.500 & 2.533 & 81.730 \\
\hline
\end{tabular}

(b)

\begin{tabular}{ll}
\hline Fixation index & Estimated value \\
\hline$\Phi_{\mathrm{IS}}$ & 0.019 \\
$\Phi_{\mathrm{SC}}$ & $\mathbf{0 . 0 3 4}$ \\
$\Phi_{\mathrm{CT}}$ & $\mathbf{0 . 1 3 7}$ \\
$\Phi_{\mathrm{IT}}$ & $\mathbf{0 . 1 8 3}$ \\
\hline
\end{tabular}

(c)

\begin{tabular}{lccl}
\hline Population & AR & FL & CT \\
\hline AR & - & 0.16 & 0.17 \\
FL & $\leq 0.01$ & - & 0.03 \\
CT & $\leq 0.01$ & $\leq 0.01$ & - \\
\hline
\end{tabular}

AR, Argentina; FL, Florida; CT, Connecticut.

were no significant differences in mean relatedness of either adult males or females with respect to juveniles (putative offspring) within nests as evidenced by the overlap in 95\% CI (Table 3). In AR, however, mean relatedness of both adult females and males to juveniles was significantly $<0.5(P<0.05$ as indicated by the $95 \%$ CI; Table 3), while in FL this was not the case.

To identify first-order relatives, we first established the minimum cut-off relatedness value for which we had reasonable confidence that a pair were indeed true first-order relatives. This step was fundamental for examining EPP, IBP and long-distance dispersal. Queller \& Goodnight's (1989) index cut-off values for determining first-order relationships were $\geq 0.5$ in AR and $\geq 0.55$ in FL. These values have a $7.4 \%$ probability of being half-sibs and a $0.6 \%$ probability of being unrelated based on the empirical distribution of relatedness values obtained through simulating 1000 dyads for each of four relatedness categories (Data S2, Supporting information). These values minimize the chance of a false positive, but also significantly increase the chance of a false negative as the cut-off values include $\sim 50 \%$ of the distribution of relatedness values observed for simulated full-sibs and parent-offspring pairs. Nevertheless, we believe that conservative levels should be applied to identify EPP and dispersal distance in the absence of corroborating observational data.

To identify putative extra-pair nestlings, we applied the five criteria outlined earlier (see Material and methods) by first identifying adult-juvenile pairs that shared at least one allele at every locus in $22(85 \%)$ adults and $30(88 \%$ ) juveniles (660 pairwise comparisons) in AR and $83(91 \%)$ adults and $56(96 \%)$ juveniles (4648 pairwise comparisons) in FL that had complete genotypes (criterion 1). The data yielded an estimate of $P(\Phi)=0.4$ for AR and $P(\Phi)=0.8$ for FL. In total, 53 adult-juvenile pairs were identified that shared at least one allele at every locus ( $8 \%$ of total comparisons) in AR and 485 (10\% of total comparisons) in FL. Of these, 36 (AR) and 34 (FL) met criterion 2 of $\leq 0.15$ probability that an

Table 3 Population structure of pairwise relatedness values. Mean Queller \& Goodnight's (1989) relatedness values for pairwise comparisons of individuals in different relatedness categories across AR and FL sampling sites

\begin{tabular}{|c|c|c|c|c|c|}
\hline \multirow[b]{3}{*}{ Pairwise comparisons } & \multirow{3}{*}{$\begin{array}{l}\text { Expected } \\
\text { value } \\
\text { under } \\
\text { sexual } \\
\text { monogamy }\end{array}$} & \multicolumn{4}{|l|}{ Site } \\
\hline & & \multicolumn{2}{|l|}{$\mathrm{AR}$} & \multicolumn{2}{|l|}{ FL } \\
\hline & & $N$ & Mean $(95 \% \mathrm{CI})$ & $N$ & Mean $(95 \% \mathrm{CI})$ \\
\hline Individuals within nests & 0.50 & 146 & $0.39(0.349,0.433)$ & 216 & $0.40(0.395,0.446)$ \\
\hline Individuals among nests & 0.00 & 1624 & $-0.04(-0.046,-0.026)$ & 10810 & $-0.01(-0.014,-0.005)$ \\
\hline Adult females to juveniles within nests & 0.50 & 33 & $0.44(0.387,0.497)$ & 41 & $0.49(0.426,0.554)$ \\
\hline Adult females to juveniles among nests & 0.00 & 409 & $-0.04(-0.058,-0.021)$ & 2627 & $0.00(-0.013,0.004)$ \\
\hline Adult males to juvenile within nests & 0.50 & 38 & $0.37(0.301,0.437)$ & 48 & $0.52(0.455,0.592)$ \\
\hline Adult males to juveniles among nests & 0.00 & 404 & $-0.05(-0.069,-0.029)$ & 2562 & $-0.02(-0.025,-0.007)$ \\
\hline
\end{tabular}

AR, Argentina; FL, Florida. 
adult-juvenile pair that shares at least one allele at every locus is not a true parent-offspring pair given the observed allele frequency $(P(\Phi \mid \lambda))$; of these, 15 (AR) and five (FL) met criterion 3 (relatedness values equal to or larger than the cut-off value for first-order relatives) and criterion 4 (were sampled from nests within $100 \mathrm{~m}$ of each other); of these, 12 (AR) and three (FL) were adult/juvenile pairs sampled from the same nest. From the remainder, three (AR) and two (FL) pairs, involved adult/juvenile pairs sampled from different nests. Of these, only one pair (AR) met criterion 5 (with the putative extra-pair parent having $r_{\mathrm{xyQG}}=-0.26$ and -0.13 with respect to the breeding adults in the sampled nest). Although this potential instance of EPP met all criteria, the nestling in question exhibited a pairwise relatedness value just below the first-order relationship cut-off value $\left(r_{\mathrm{xyQG}}=0.43\right)$ with the social male attending the nest. Consequently, we are reluctant to reject the null hypothesis that the breeding pair was in fact monogamous.

Because criteria 2 and 3 are distinct measures of relatedness, it was imperative to establish that they were not redundant. Regression of $P(\Phi \mid \lambda)$ onto relatedness values yielded a nonsignificant relationship in AR $\left(P=0.091, R^{2}=0.05\right)$ and a negative relationship in FL $\left(P=0.013 ; R^{2}=0.01\right)$; however, in this case, the regression was only able to explain $\sim 1 \%$ of the observed variation. Therefore, we are confident that criteria 2 and 3 are complementary rather than redundant.

\section{Dispersal distance}

To measure long-distance dispersal events, we examined the distribution of geographical distances among adult individuals found to be first-order relatives within $\mathrm{AR}$ and $\mathrm{FL}$, respectively. In $\mathrm{AR}$, using the empirically determined relatedness cut-off value, we identified three first-order adult pairs (comprising five individuals) from different nests. Two pairs involved nests $\sim 510 \mathrm{~m}$ apart, and the third involved nests over $9600 \mathrm{~m}$ apart (Fig. 2). In FL, we found 61 first-order adult pairs (comprising 58 individuals) from different nests, covering distances between 52 and $106000 \mathrm{~m}$. The spatial distribution of first-order relatives in FL is highly skewed, with a median of $22900 \mathrm{~m}$ and a $75 \%$ quartile at $\sim 48000 \mathrm{~m}$ (Fig. 2).

\section{Discussion}

\section{Evidence for high propagule pressure}

In the classic model of invasion biology, introduced populations are predicted to start with a small, and thus genetically depauperate propagule (Allendorf \& Lundquist 2003). However, theory and empirical data
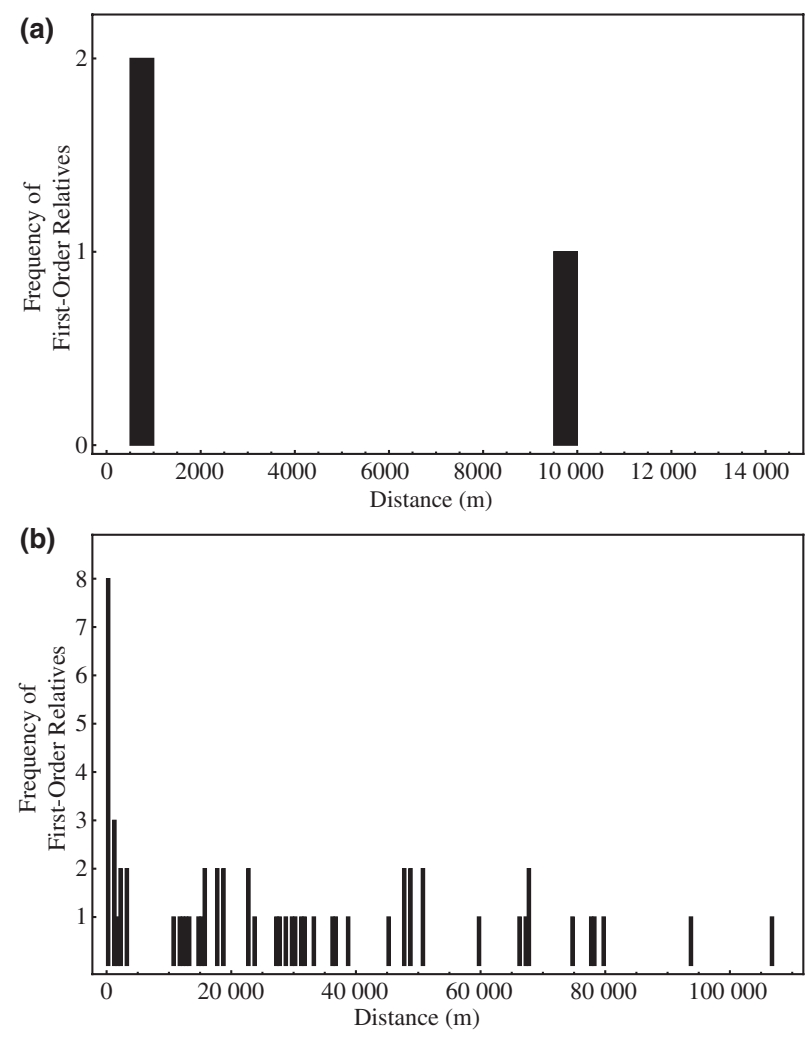

Fig. 2 Distribution of distances between nests with first-order adult relatives. (a) Argentina and (b) Florida.

on small populations suggest that such a scenario would be unlikely to lead to a viable population (Caughley 1994), inhibiting successful establishment and subsequent invasion (Sakai et al. 2001). New evidence indicates that successful invasions are often associated with high propagule pressure (Duncan 1997; Green 1997; Hayes \& Barry 2008; Lockwood et al. 2005; Simberloff 2009; Veltman et al. 1996; Von Holle \& Simberloff 2005), which acts to minimize the demographic and genetic risks associated with small populations. In birds, the international pet trade is a potential source of high propagule pressure, contributing to the increase in invasive bird species (Carrete \& Tella 2008). Thus, for species introductions involving high propagule pressure, the classic invasion model's prediction of low genetic diversity within invasive (introduced) populations when compared to native (source) populations may be invalid (Simberloff 2009).

Three patterns at neutral loci can be found in invasive sites with high propagule pressure: (i) comparable levels of genetic diversity between native and invasive sites and little evidence for genetic bottleneck in the invasive sites (Wares et al. 2005); (ii) invasive sites with a longer history of propagule pressure usually have higher levels of genetic diversity than sites with shorter histories (Simberloff 2009); and (iii) if propagule pres- 
sure involves more then one source population, then linkage disequilibrium would be expected in introduced sites as a result of recent admixture (Kolbe et al. 2007).

The comparison of genetic variation at microsatellite loci across native and invasive sites of the monk parakeet revealed little loss in the invasive range relative to the sampled site in the native range (Table 1), even after corrections for sample size. In particular, mean losses in allelic richness and in expected heterozygosity was not statistically significant in the FL site when compared to AR. Mean loss in observed heterozygosity was statistically significant, but was not much larger than the loss in expected heterozygosity. In CT, while losses of genetic diversity were significant relative to $A R$ (except for mean loss of observed heterozygosity), this is not unexpected under scenarios of multiple introductions, and the observed values are within the reported range for other invasive species where high propagule pressure has been independently documented (maximum loss of allelic richness $62 \%$, and maximum loss of expected heterozygosity 56\%, Dlugosch \& Parker 2008). Furthermore, the failure of direct tests to detect any signatures of a genetic bottleneck in the invasive sites was consistent with the observation of little loss in expected heterozygosity and allelic richness. These results match the first expected pattern of comparable levels of genetic diversity between native and invasive populations.

The second pattern, which focuses on the temporal component of propagule pressure, was only weakly observed in our data set. Christmas Bird Count data suggest that FL has had a longer history of releases than CT (National Audubon Society 2002), which is corroborated by the smaller losses in expected and observed heterozygosity, and allelic richness relative to AR (Table 1). However, at the present time alternative explanations seem equally plausible. For instance, monk parakeets seem sensitive to number of frost-days (number of days with minimum air temperature $<0{ }^{\circ} \mathrm{C}$, Strubbe \& Matthysen 2009), thus harsher winters in CT could have contributed to smaller population sizes, and therefore increased loss of genetic variation through genetic drift. Sampling of populations along the same latitude (e.g., along the Gulf Coast) with different times of establishment could assist in further evaluating the temporal component in monk parakeet propagule pressure, while controlling for potentially confounding abiotic factors.

Finally, we find some evidence for multiple source populations within the established United States invasive populations. First, we observed a number of private alleles across the invasive sites relative to the native site, some of which were found at high relative frequencies (Data S1, Supporting information). Second, significant structure was detected between invasive and native sites (Table 3). While these patterns may be because of genetic drift, it is possible that admixture among individuals from source populations with differing allele frequencies could be the underlying cause. Finally, two pairs of loci were in linkage disequilibrium in the invasive sites, but not in the native site, also indicating possible admixture between two or more isolated source populations (Hartl \& Clark 2007). Collectively, these results suggest that monk parakeets may have significant structure across the native range and that invasive sites may include descendants of released birds originating from genetically differentiated parts of the native range.

Thus, of the three patterns expected under a scenario of high propagule pressure, we have strong evidence for at least one and weak support for the other two. Comparable levels of genetic variation across native and invasive populations is possibly the clearest indication of high propagule pressure (Dlugosch \& Parker 2008; Simberloff 2009), while the other two are concerned with patterns arising from variation among invasive sites in propagule pressure and about the sources of propagules, respectively. Our data, in combination with previous genetic evidence for the role of the international pet bird trade in monk parakeet invasion in the United States (Russello et al. 2008), show strong support for the hypothesis proposed by Van Bael \& Pruett-Jones (1996) that high propagule pressure was a significant driver in this species' invasion process. This conclusion adds to the assertions by Carrete \& Tella (2008) that wild-caught species involved in international pet trade have a high probability of becoming invasive.

\section{Evidence for sexual monogamy}

Parrot behavioural studies to date have found most species to be socially monogamous; however, there is a paucity of studies examining genetic parentage in this group (Spoon 2006), despite observations of extra-pair copulations (EPC) in some socially monogamous parrots (e.g., Melopsittacus undulatus, Brockway 1964; and Eolophus roseicapillus, Rowley 1990). In the only study that we are aware of that has explicitly investigated sexual monogamy in parrots, the authors did not find any evidence for extra-pair parentage (Masello et al. 2002), consistent with the view that most parrots are sexually monogamous. Like other parrots, monk parakeets have long been considered socially monogamous (Eberhard 1998; Navarro et al. 1992, 1995), but until now there has been no conclusive evidence to support this hypothesis.

Here, we test the prediction that adults and juveniles within nests should have a mean relatedness of 0.5 (expected for a parent-offspring pair) and 0.0 (expected for an unrelated pair) among nests (Blouin et al. 1996). 
Our analysis of relatedness of adult males to juveniles and adult females to juveniles within and among nests in both AR and FL corroborate the hypothesis of sexual monogamy (Table 3). However, mean values in $A R$ were lower than expected for all categories. This result may have occurred because our sampling in AR was spatially limited and probably biased towards related adults, potentially influencing our baseline for calculating population allele frequency distributions. Such a pattern is expected to skew estimates of allele frequency distributions leading to underestimation of relatedness (Queller \& Goodnight 1989). A larger sample of adults across a wider geographical range would be needed to ascertain whether this observed difference in mean relatedness between AR and FL is indeed biologically significant.

We also investigated the occurrence and frequency of extra-pair fertilization by exploring allele sharing among adults and juveniles. Our analysis found one potential instance of EPP in AR and none in FL; in neither site was there evidence of IBP. In the single case that met all our criteria, the social father of the nestling in question has a relatedness value that is close to our empirical cut-off value $\left(r_{\mathrm{xyQG}}=0.43\right)$, and above the usual cut-off value for first-order relationship of 0.37 (Blouin et al. 1996; Russello \& Amato 2004). Thus, we are inclined to accept the more parsimonious hypothesis that the social father is also the true father, and therefore conclude that there is no strong evidence for EPP in either site. In our examination of allele sharing following the five criteria detailed earlier, we discarded a number of adult-juvenile pairs that were found to share at least one allele at every locus, raising the possibility that our approach was too conservative and has considerably underestimated the frequency of EPP. However, we have several reasons to believe that this was not the case.

First, when simulating five loci with 10 alleles of equal frequency each, Christie (2010) found that, in moderate sample sizes $(N=200)$ of unrelated adults plus juveniles, roughly 1000 pairs shared at least one allele at every locus by chance alone; increasing the number of loci to 10 with the same number of alleles decreased the false-positive rate to approximately 100 pairs. In the current study, we analysed 52 (AR) and 139 (FL) individuals (adults plus juveniles) at eight loci that exhibited wide variation in numbers of alleles and allele frequency distributions. Thus, a relatively large number of adult-juvenile pairs would be expected to share at least one allele at every locus by chance alone, as indicated by the relatively high $P(\Phi)$ observed in both sites. Second, monk parakeet breeding behaviour does not suggest there are significant incentives for EPCs (Griffith et al. 2002). In particular, interspecific analyses have predicted (Birkhead \& Møller 1996) and shown (Hoi-Leitner et al. 1999) EPP to be negatively correlated with the degree of importance of male parental care to female breeding success (Møller 2000). In monk parakeets, once a female has begun egg-laying, she rarely leaves the nest, and the male assumes the responsibility of foraging for the incubating female; and once the young hatch, the male collaborates with the female to feed them (Eberhard 1998). When male parental care is essential, females are expected to incur a high fitness cost for seeking EPCs if males suspect cheating and withhold care (Petrie \& Kempenaers 1998). Males seeking EPCs are also expected to incur costs because of reduced protection of the female and decreased reproductive success resulting from reduced paternal care (Westneat et al. 1990).

Finally, it is possible that by setting the maximum distance among nests at $100 \mathrm{~m}$ (criterion 4), we did not detect all possible EPC events. This distance was chosen because it accurately reflects colony boundaries at the Argentina site (Eberhard 1998), and thus it encompasses the individuals most likely to be involved in EPC (for reasons described earlier). Nevertheless, colony boundaries in birds are not necessarily distinct and can vary among populations of the same species (Jovani et al. 2008; Jovani \& Tella 2007), and thus criterion 4 may be too restrictive in the FL site. To explore the effect of relaxing this criterion, we examined putative parentoffspring pairs involving birds from nests up to $1000 \mathrm{~m}$ apart in both AR and FL sites that met criteria 1 through 3 (this distance was arbitrarily chosen as one order of magnitude larger than $100 \mathrm{~m}$ and does not reflect any prior biological knowledge). In doing so, an additional two putative parent-offspring pairs in each site are found at distances ranging from 220 to $540 \mathrm{~m}$. However, in all four cases, the adults have relatedness values above the cut-off values, and thus do not meet criterion 5. Therefore, given the potential for false positives in our data set, combined with the high degree of male parental care displayed by monk parakeets, we feel confident that our approach reflects a conservative estimate of the degree of extra-pair activity in this species.

Our results indicate that the monk parakeet is sexually monogamous across native and invasive sites. Under a classical scenario of invasion, sexually monogamous species are unlikely to be successful invaders, as they are expected to have higher extinction risk than polygamous species when occurring in small populations (Legendre et al. 1999). It remains possible that monk parakeets have adopted a mating strategy with increased levels of EPP in the invasive range to buffer against extinction risk, as has been demonstrated in the lesser spotted woodpecker (Picoides minor, Rossmanith et al. 2006). However, we do not have any evidence to suggest that individuals from native and invasive sites 
are employing different mating strategies. Instead, the evidence presented in the previous section suggests that in a situation of high propagule pressure, a sexually monogamous species can become a successful invader.

\section{Evidence for long-distance dispersal}

Long-distance natal dispersal is common in birds (Mayr 1966; Paradis et al. 1998). Even relatively small nonmigratory birds similar in size to the monk parakeet are known to have natal dispersal distances of up to $350 \mathrm{~km}$ (Paradis et al. 1998). An observational study in the monk parakeet's native range concluded that most natal dispersal occurs over short distances, with the majority occurring at $\sim 500 \mathrm{~m}$ and no further than $2000 \mathrm{~m}$ from the natal site (Martín \& Bucher 1993). However, this study was carried out over a relatively restricted spatial scale (with distance between censused nests not exceeding $12000 \mathrm{~m}$ ). Our conservative approach based on genetically inferred pedigree relationships found three instances of first-order adult relatives among nests in AR, two of which were within the dispersal range previously estimated, but the third was almost five times further than the largest distance previously recorded (9600 m; Fig. 2). Over a much larger sampling spatial scale in FL, we found 61 instances of first-order adult relatives among nests spanning distances from 52 to $105000 \mathrm{~m}$ (Fig. 2).

Two explanations may account for the significant discrepancy in estimates of natal dispersal between our study and that of Martín \& Bucher (1993). First, it is possible that our genetic approach is overestimating pedigree relationships, and therefore overestimating dispersal capacity. We do not believe this to be true for two reasons: (i) we used a group of eight hypervariable loci that collectively have high power to distinguish among individuals (probability of identity across all loci was $6.4 \times 10^{-8}$ for AR and $6.3 \times 10^{-7}$ for FL, Russello et al. 2007); and (ii) we employed a conservative cut-off value to determine first-order relatives precisely to reduce the rate of false positives. Alternatively, it is possible that Martín \& Bucher (1993) underestimated dispersal capacity by choosing an inadequate spatial sampling scale to accurately capture maximum dispersal distances in monk parakeets. As shown by Paradis et al. (1998), avian natal dispersal distance distributions often have long tails that usually go undetected because of restricted spatial sampling scales. Thus, we contend that the monk parakeet has the potential to disperse over relatively large distances (on the order of at least $100 \mathrm{~km}$ ). This characteristic, as observed by Mayr (1965), is common among colonizing bird species, and probably an important factor contrib- uting to their spread in the invasive range. Furthermore, this corroborates the inferences made by Van Bael \& Pruett-Jones (1996) that the species is spreading without human assistance.

An alternative hypothesis compatible with both our observations and Martín \& Bucher's (1993) is that monk parakeets disperse further in the invasive range in relation to the native range, a phenomenon that has been observed in other bird species (Able \& Belthoff 1998; Cox 2004). Unfortunately, our current sampling does not allow us to evaluate whether median dispersal distances are larger in the invasive range vs. the native range. Additional sampling in the native range would be required to address this fundamental question and to further understand the processes underlying monk parakeet invasion success. More generally, the genetic inferences obtained here could be complemented by intense mark-recapture studies (e.g., Alcaide et al. 2009).

\section{Conclusions}

In this study, we examined intrinsic and extrinsic factors contributing to monk parakeet invasion success. We test hypotheses relating to propagule pressure, sexual monogamy and dispersal capacity in the invasive monk parakeet. Our data and analyses provide evidence of long-distance dispersal capacity and sexual monogamy, both of which probably play a role in the species invasive success. Perhaps more importantly, our results provide empirical evidence in support of the hypothesis that high propagule pressure is an important factor in invasion success. Mounting evidence suggests that propagule pressure is much more heterogeneous than proposed in the classical model of invasion, and thus a review of the model may be warranted to better explain and understand the invasion process.

\section{Acknowledgements}

We thank the Ortíz-Basualdo family and personnel at Estancia Santa Ana de Carpinchorí and Estancia Palmira for their hospitality and assistance with fieldwork in Argentina. George Amato provided assistance during the early stages of this work. We would also like to acknowledge the contributions of J. Wright, D. Hoffmeier and J. Lindsay with Florida Power and Light Company, who provided monk parakeet samples and nest locations from south Florida; and $\mathrm{M}$. Chandler, who provided monk parakeet samples and nest locations from Connecticut. We also thank Philippe Henry, Dany Garant and four anonymous reviewers, who provided constructive suggestions that improved the manuscript. Funding was provided by the American Philosophical Society (MAR), Canadian Foundation for Innovation (MAR), the National Institutes of Health grant number S06 GM008136 (TFW) and the United States Department of Agriculture (MLA). 


\section{References}

Able KP, Belthoff JR (1998) Rapid 'evolution' of migratory behaviour in the introduced house finch of eastern North America. Proceedings of the Royal Society of London Series B-Biological Sciences, 265, 2063-2071.

Alcaide M, Serrano D, Tella JL, Negro JJ (2009) Strong philopatry derived from capture-recapture records does not lead to fine-scale genetic differentiation in lesser kestrels. Journal of Animal Ecology, 78, 468-475.

Allendorf FW, Lundquist LL (2003) Population biology, evolution, and control of invasive species. Conservation Biology, 17, 24-30.

Arnold KE, Owens IPF (2002) Extra-pair paternity and egg dumping in birds: life history, parental care and the risk of retaliation. Proceedings of the Royal Society of London Series B-Biological Sciences, 269, 1263-1269.

Bessa-Gomes C, Danek-Gontard M, Cassey P et al. (2003) Mating behaviour influences extinction risk: insights from demographic modelling and comparative analysis of avian extinction risk. Annales Zoologici Fennici, 40, 231-245.

BirdLife International (2009) Myiopsitta monachus. In: IUCN Red List of Threatened Species. Version 2009.9. www.iucnredlist.org. IUCN, Gland, Switzerland.

Birkhead TR, Møller AP (1996) Monogamy and sperm competition in birds. In: Partnerships in Birds: The Study of Monogamy (ed. Black JM), pp. 323-343. Oxford University Press, Oxford, UK.

Blackburn TM, Cassey P, Lockwood JL (2009a) The role of species traits in the establishment success of exotic birds. Global Change Biology, 15, 2852-2860.

Blackburn TM, Lockwood JL, Cassey P (2009b) Avian Invasions: The Ecology and Evolution of Exotic Birds. Oxford University Press, Oxford.

Blouin MS, Parsons M, Lacaille V, Lotz S (1996) Use of microsatellite loci to classify individuals by relatedness. Molecular Ecology, 5, 393-401.

Brockway BF (1964) Ethological studies of the budgerigar: reproductive behavior. Behaviour, 23, 294-323.

Campbell TS (1996) Northern range expansion of the brown anole (Anolis sagrei) in Florida and Georgia. Herpetological Review, 27, 155-157.

Carrete M, Tella JL (2008) Wild-bird trade and exotic invasions: a new link of conservation concern? Frontiers in Ecology and the Environment, 6, 207-211.

Cassey P (2002) Life history and ecology influences establishment success of introduced land birds. Biological Journal of the Linnean Society, 76, 465-480.

Cassey P, Blackburn TM, Sol S, Duncan RP, Lockwood JL (2004) Global patterns of introduction effort and establishment success in birds. Proceedings of the Royal Society of London Series B-Biological Sciences, 271, S405-S408.

Caughley G (1994) Directions in conservation biology. Journal of Animal Ecology, 63, 215-244.

Christie MR (2010) Parentage in natural populations: novel methods to detect parent-offspring pairs in large data sets. Molecular Ecology Resources, 10, 115-128.

Cox GW (2004) Alien Species and Evolution: The Evolutionary Ecology of Exotic Plants, Animals, Microbes, and Interacting Native Species. Island Press, Washington, DC.
Dlugosch KM, Parker IM (2008) Founding events in species invasions: genetic variation, adaptive evolution, and the role of multiple introductions. Molecular Ecology, 17, 431-449.

Duncan RP (1997) The role of competition and introduction effort in the success of passeriform birds introduced to New Zealand. American Naturalist, 149, 903-915.

Duncan R, Blackburn T, Sol D (2003) The ecology of bird introductions. Annual Review of Ecology, Evolution, and Systematics, 34, 71-98.

Eberhard JR (1998) Breeding biology of the monk parakeet. The Wilson Bulletin, 110, 463-473.

Emlen ST (1990) Observations on a captive colony of Quaker parakeets. AFA Watchbird, 27, 26-29.

Excoffier L, Smouse PE, Quattro JM (1992) Analysis of molecular variance inferred from metric distances among DNA haplotypes: application to human mitochondrial DNA restriction data. Genetics, 131, 479-491.

Excoffier L, Laval G, Schneider S (2005) ARLEQUIN (version 3.0): An integrated software package for population genetics data analysis. Evolutionary Bioinformatics Online, 47-50.

Forshaw JM, Cooper WT (1989) Parrots of the World, 3rd (rev.) edn. Lansdowne Editions, Blandford.

Gonçalves da Silva A, Russello MA (2010) iREL: Software for implementing pairwise relatedness estimators and evaluating their performance. Conservation Genetics Resources, doi: 10.1007/s12686-010-9292-4.

Green RE (1997) The influence of numbers released on the outcome of attempts to introduce exotic bird species to New Zealand. Journal of Animal Ecology, 66, 25-35.

Griffith SC, Owens IPF, Thuman KA (2002) Extra pair paternity in birds: a review of interspecific variation and adaptive function. Molecular Ecology, 11, 2195-2212.

Griffiths R, Double MC, Orr K, Dawson RJG (1998) A DNA test to sex most birds. Molecular Ecology, 7, 1071-1075.

Hartl DL, Clark AG (2007) Principles of Population Genetics, 4th edn. Sinauer Associates Publishers, Sunderland, Mass.

Hayes KR, Barry SC (2008) Are there any consistent predictors of invasion success? Biological Invasions, 10, 483-506.

Hoi-Leitner M, Hoi H, Romero-Pujante M, Valera F (1999) Female extra-pair behaviour and environmental quality in the serin (Serinus serinus): a test of the 'constrained female hypothesis'. Proceedings of the Royal Society of London Series B-Biological Sciences, 266, 1021-1026.

Jovani R, Tella JL (2007) Fractal bird nest distribution produces scale-free colony sizes. Proceedings of the Royal Society B-Biological Sciences, 274, 2465-2469.

Jovani R, Serrano D, Ursua E, Tella JL (2008) Truncated power laws reveal a link between low-level behavioral processes and grouping patterns in a colonial bird. PLOS ONE, 3, e1992.

Kalinowski ST, Taper ML, Marshall TC (2007) Revising how the computer program CERVUS accommodates genotyping error increases success in paternity assignment. Molecular Ecology, 16, 1099-1106.

Koenig WD, VanVuren D, Hooge PN (1996) Detectability, philopatry, and the distribution of dispersal distances in vertebrates. Trends in Ecology \& Evolution, 11, 514-517.

Kolbe JJ, Glor RE, Schettino LRG et al. (2004) Genetic variation increases during biological invasion by a Cuban lizard. Nature, 431, 177-181. 
Kolbe JJ, Glor RE, Schettino LRG et al. (2007) Multiple source, admixture, and genetic variation in introduced Anolis lizard populations. Conservation Biology, 21, 1612-1625.

Lande R (1988) Genetics and demography in biological conservation. Science, 241, 1455-1460.

Legendre S, Clobert J, Moller AP, Sorci G (1999) Demographic stochasticity and social mating system in the process of extinction of small populations: the case of passerines introduced to New Zealand. American Naturalist, 153, 449-463.

Lever C, Gillmor R (1987) Naturalized Birds of the World. Longman Scientific \& Technical, Wiley, New York, NY.

Lockwood J, Cassey P, Blackburn T (2005) The role of propagule pressure in explaining species invasions. Trends in Ecology \& Evolution, 20, 223-228.

Marchetti MP, Moyle PB, Levine R (2004) Invasive species profiling: exploring the characteristics of non-native fishes across invasion stages in California. Freshwater Biology, 49, 646-661.

Marshall TC, Slate J, Kruuk LEB, Pemberton JM (1998) Statistical confidence for likelihood-based paternity inference in natural populations. Molecular Ecology, 7, 639-655.

Martín LF, Bucher EH (1993) Natal dispersal and first breeding age in monk parakeets. The Auk, 110, 930-933.

Masello JF, Sramkova A, Quillfeldt P, Epplen JT, Lubjuhn T (2002) Genetic monogamy in burrowing parrots Cyanoliseus patagonus? Journal of Avian Biology, 33, 99-103.

Mayr E (1965) The nature of colonization in birds. In: The Genetics of Colonizing Species: Proceedings of the First International Union of Biological Sciences Symposia on General Biology (eds Baker HG, Stebbins GL), pp. 29-43, Academic Press, New York, NY.

Mayr E (1966) Animal Species and Evolution. Harvard University Press, Cambridge Mass.

Møller AP (2000) Male parental care, female reproductive success, and extrapair paternity. Behavioral Ecology, 11, 161168.

National Audubon Society (2002) The Christmas bird count historical results, http://www.audubon.org/bird/cbc; (accessed May 5, 2009).

Navarro JL, Bucher EH (1990) Growth of monk parakeets. The Wilson Bulletin, 102, 520-525.

Navarro JL, Bucher EH (1992) Annual variation in the timing of breeding of the monk parakeet in relation to climatic factors. The Wilson Bulletin, 104, 545-549.

Navarro JL, Martella MB, Bucher EH (1992) Breeding season and productivity of monk parakeets in Cordoba, Argentina. The Wilson Bulletin, 104, 413-424.

Navarro JL, Martella MB, Bucher EH (1995) Effects of laying date, clutch size, and communal nest size on the reproductive success of Monk Parakeets. The Wilson Bulletin, 107, 742-746

Paradis E, Baillie SR, Sutherland WJ, Gregory RD (1998) Patterns of natal and breeding dispersal in birds. Journal of Animal Ecology, 67, 518-536.

Petrie M, Kempenaers B (1998) Extra-pair paternity in birds: explaining variation between species and populations. Trends in Ecology \& Evolution, 13, 52-58.

Piry S, Luikart G, Cornuet JM (1999) BOTTLENECK: a computer program for detecting recent reductions in the effective population size using allele frequency data. Journal of Heredity, 90, 502-503.
Pruett-Jones S, Newman CM, Lindsay JR (2005) Population growth of monk parakeets in Florida. Florida Field Naturalist, 33, 1-14.

Queller DC, Goodnight KF (1989) Estimating relatedness using genetic markers. Evolution, 43, 258-275.

Rossmanith E, Grimm V, Blaum N, Jeltsch F (2006) Behavioural flexibility in the mating system buffers population extinction: lessons from the lesser spotted woodpecker Picoides minor. Journal of Animal Ecology, 75, 540548 .

Rowley I (1990) Behavioural Ecology of the Galah Eolophus roseicapillus in the Wheatbelt of Western Australia. Surrey Beatty \& Sons, Chipping Norton, NSW.

Russello MA, Amato G (2001) Application of a noninvasive, PCR-based test for sex identification in an endangered parrot, Amazona guildingii. Zoo Biology, 20, 41-45.

Russello MA, Amato G (2004) Ex situ population management in the absence of pedigree information. Molecular Ecology, 13, 2829-2840.

Russello MA, Saranathan V, Buhrman-Deever S, Eberhard J, Caccone A (2007) Characterization of polymorphic microsatellite loci for the invasive monk parakeet (Myiopsitta monachus). Molecular Ecology Notes, 7, 990-992.

Russello MA, Avery ML, Wright TF (2008) Genetic evidence links invasive monk parakeet populations in the United States to the international pet trade. BMC Evolutionary Biology, 8, 217.

Sakai AK, Allendorf FW, Holt JS et al. (2001) The population biology of invasive species. Annual Review of Ecology and Systematics, 32, 305-332.

Simberloff D (2009) The role of propagule pressure in biological invasions. Annual Review of Ecology, Evolution, and Systematics, 40, 81-102.

Spoon TR (2006) Parrot reproductive behavior, or who associates, who mates, and who cares? In: Manual of Parrot Behavior (ed. Luescher AU), pp. 63-78. Wiley-Blackwell, Ames, Iowa.

Spreyer MF, Bucher EH (1998) Monk parakeet (Myiopsitta monachus). In: The Birds of North America Online (ed. Poole A), Cornell Lab of Ornithology. Avilable from the Birds of North America Online http://bna.birds.cornell.edu/bna/ species/322.

Strubbe D, Matthysen E (2009) Establishment success of invasive ring-necked and monk parakeets in Europe. Journal of Biogeography, 36, 2264-2278.

Suarez AV, Holway DA, Tsutsui ND (2008) Genetics and behavior of a colonizing species: the invasive argentine ant. American Naturalist, 172, S72-S84.

Van Bael S, Pruett-Jones S (1996) Exponential population growth of monk parakeets in the United States. The Wilson Bulletin, 108, 584-588.

Van de Casteele T, Galbusera P, Matthysen E (2001) A comparison of microsatellite-based pairwise relatedness estimators. Molecular Ecology, 10, 1539-1549.

Van Oosterhout C, Hutchinson WF, Wills DPM, Shipley P (2004) MICRO-CHECKER: software for identifying and correcting genotyping errors in microsatellite data. Molecular Ecology Notes, 4, 535-538.

Veltman CJ, Nee S, Crawley MJ (1996) Correlates of introduction success in exotic New Zealand birds. American Naturalist, 147, 542-557. 
Von Holle B, Simberloff D (2005) Ecological resistance to biological invasion overwhelmed by propagule pressure. Ecology, 86, 3212-3218.

Wares JP, Hughes AR, Grosberg RK (2005) Mechanisms that drive evolutionary change: insights from species introductions and invasions. In: Species Invasions: Insights into Ecology, Evolution, and Biogeography (eds Sax DF, Stachowicz JJ, Gaines SD), pp. 229-257. Sinauer Associates, Sunderland, Mass.

Westneat DF, Sherman PW, Morton ML (1990) The ecology and evolution of extra-pair copulations in birds. Current Ornithology, 7, 331-369.

Wright TF, Eberhard J, Hobson EA, Avery ML, Russello MA (in press) Behavioral flexibility and species invasions: the adaptive flexibility hypothesis. Ethology, Ecology and Evolution (in press).

Anders Gonçalves da Silva is a postdoctoral fellow who is interested in applying population genetic theory and techniques to answer questions of conservation relevance. Jessica Eberhard is a Research Assistant Professor who studies the evolution and behaviour of parrots. Tim Wright is an Associate
Professor who studies behaviour and evolution and their interactions in the conservation of parrots. Michael Avery is a Supervisory Research Wildlife Biologist who conducts research on behaviour and ecology of invasive wildlife. Michael Russello is an Assistant Professor with research interests in vertebrate conservation genetics, molecular ecology and population genomics.

\section{Supporting information}

Additional supporting information may be found in the online version of this article.

Data S1 Heat map comparing relative allele frequencies across three sampling sites of monk parakeets (Myiopsitta monachus).

Data S2 Empirical distributions of Queller \& Goodnight's (1989) relatedness values.

Please note: Wiley-Blackwell are not responsible for the content or functionality of any supporting information supplied by the authors. Any queries (other than missing material) should be directed to the corresponding author for the article. 